\title{
Decreased hyaluronan in airway smooth muscle cells from patients with asthma
} and COPD

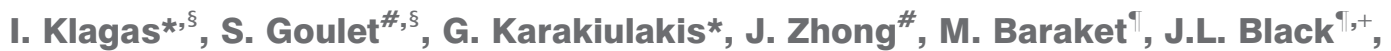 \\ E. Papakonstantinou* and M. Roth ${ }^{\#, \oplus_{,}+}$
}

ABSTRACT: Glycosaminoglycans (GAG) are essential extracellular matrix molecules which regulate tissue flexibility, a parameter that is reduced in airways of patients with asthma and chronic obstructive pulmonary disease (COPD). We investigated the expression of GAG and their metabolising enzymes in primary human airway smooth muscle cells (ASMC) obtained from healthy donors (controls) and patients with asthma or COPD.

Total GAG synthesis was assessed by $\left[{ }^{3} \mathrm{H}\right]$-glucosamine incorporation. GAG were isolated, purified, fractionated by electrophoresis and characterised using specific GAG-degrading enzymes. Secretion of hyaluronic acid (HA) by ASMC from patients with asthma or COPD was significantly decreased compared with controls. RT-PCR analysis and western blotting revealed that this decrease was associated with a significant reduction in the expression of HA synthase-1 and -2 and a significant increase of hyaluronidase-1. Furthermore, the expression of the HA receptor CD44 was significantly decreased, whereas the receptor for HA-mediated motility was not expressed in asthma or COPD.

Our results indicate that there is a decreased expression of HA in asthma and COPD associated with a synergistic regulation of HA metabolising enzymes that may regulate the pathological airway remodelling in these lung diseases.

KEYWORDS: Airway smooth muscle cells, asthma, CD44, chronic obstructive pulmonary disease, glycosaminoglycans, hyaluronic acid

$\mathbf{R}$ ecent reports on asthma and chronic obstructive pulmonary disease (COPD) research have provided clear evidence that the pathologies of both diseases cannot be solely explained on the basis of a deregulated immune response, and that malfunction of structure forming cells and disturbance of the homeostasis of extracellular matrix (ECM) molecules contribute significantly to the pathology of both diseases and reflect airway remodelling [1, 2]. Tissue remodelling describes the structural alterations that occur in the lung due to prolonged chronic inflammation within the airways, and involves qualitative or quantitative changes in cell density and the composition of the ECM in the pulmonary epithelium, the basement membrane and the submucosa. Consequently, this modification in the ECM affects airway resistance, compliance and elasticity, leading eventually to loss of lung function $[1,2]$.

Recent studies have clearly indicated the outstanding contribution of airway smooth muscle cells (ASMC) to the pathology of asthma and COPD [1-5]. Furthermore, clinical studies have demonstrated that reduction of ASMC in asthma patients by thermoplasty improved quality of life and reduced symptoms and airway inflammation in the long term $[6,7]$, thus supporting the eminent role of ASMC in this pathology. Hyperplasia of airway smooth muscle bundles is a prominent pathology of the large-medium airways in asthma and of the small airways in COPD [2]. Furthermore, we have previously shown that ECM-associated glycosaminoglycans (GAG) play a central role in regulating the response of ASMC to mitogenic stimuli [8].

GAG are essential constituents of the ECM of the lung and possess important functional properties. In humans, seven GAG have been identified: chondroitin sulfate (CS)A, dermatan sulfate (DS), CSC, heparin, heparan sulfate (HS), hyaluronic acid (HA), and keratan sulfate (KS). The function of these GAG varies within the organ in which they are located. In the human lung, KS was

\section{AFFILIATIONS}

*Dept Pharmacology, School of Medicine, Aristotle University of Thessaloniki, Thessaloniki, Greece. \#Pulmonary Cell Research, Dept Research, University Hospital Basel, Basel, Switzerland.

"Dept Pharmacology, University of Sydney, and

+The Woolcock Institute for Medical Research, Sydney, Australia.

${ }^{\S}$ Both authors contributed equally to this work.

CORRESPONDENCE

E. Papakonstantinou

Dept Pharmacology

School of Medicine

Aristotle University of Thessaloniki

54124

Thessaloniki

Greece

E-mail: epap@med.auth.gr

Received:

May 082008

Accepted after revision:

Feb 242009

First published online:

March 122009

European Respiratory Journal Print ISSN 0903-1936

Online ISSN 1399-3003 
found on the apical surface of ciliated epithelial cells, CS and DS were secreted by epithelial and submucosa gland cells, and HS was reported in the ECM of tracheal tissue sections [9]. HA and the enzymes that metabolise it are also endogenous to the pulmonary environment, and HA has been isolated from the lungs of mammals (sheep, guinea pig and rat) [10], and human lung parenchyma and pleura [11]. In the lungs, the HA content is $15-150 \mathrm{mg} \cdot \mathrm{g}^{-1}$ dry weight (species specificity), which is mainly localised in the peri-bronchial and inter-alveolar/perialveolar tissue [12]. The quantity of $\mathrm{HA}$ in human lung secretions was found to be $\sim 66 \mathrm{ng} \cdot \mathrm{mL}^{-1}$ with values ranging 34-423 ng $\cdot \mathrm{mL}^{-1}[13]$.

HA is a linear polysaccharide chain, composed of repeating disaccharide units of $N$-acetyl-D-glucosamine- $\beta(1,4)$-D-glucuronic acid- $\beta(1,3)$, which exists in both a high molecular mass form $\left(1-6 \times 10^{6} \mathrm{Da}\right)$ and a polydisperse lower molecular mass form $\left(0.1-0.5 \times 10^{6} \mathrm{Da}\right)$, with the latter predominating under inflammatory conditions [14]. Polymerisation of $\mathrm{HA}$ is regulated by the action of one or more of three HA synthases (termed HAS1, HAS2, and HAS3) [15], through the joining of the glycosidic residuals to the reducing chain extremity. HA is metabolised by hyaluronidases (HYAL), mainly by HYAL1 and HYAL2, present in various tissues, including the lung [13]. The effects of HA are mainly exerted through interactions with the HA receptor CD44, which is the main receptor mediating HA signalling [16], but also by the receptor for HA-mediated motility (RHAMM) [17]. HA receptors are expressed by lung fibroblasts [18], smooth muscle and endothelial cells of normal tissue [19]. HA has diverse biological functions in migration and proliferation [8], embryonic development, tissue morphogenesis, cell growth, differentiation and ovulation [20], as well as in disease progression [21]. However, reports on the functional role of HA in chronic inflammatory lung diseases are conflicting. This may be attributed to the fact that most studies on GAG expression in chronic inflammatory lung diseases are hindered by the lack of healthy lung tissue being used as the basic control condition.

In the present study, we used primary ASMC from healthy lung tissue (control) and from patients with asthma or COPD. We investigated the expression of HA in these primary cells, and report that there is decreased expression of HA in ASMC from patients with asthma and COPD compared with controls. This decrease is associated with a reduced expression of HAS1 and HAS2 and an increased expression of HYAL1 in gene and protein levels. In addition, we found that RHAMM was expressed only by ASMC from controls.

\section{MATERIALS AND METHODS Cell cultures}

Primary cultures of ASMC were established from dissected airway muscle bundles obtained from isolated bronchi of 10 control subjects (organ donors), or from endobronchial biopsies of 11 patients with mild-to-moderate asthma and six patients with COPD, as described previously [22]. Informed written consent was obtained from each patient and approval was given by the Human Ethics Committee of the University of Sydney and the Central Sydney Area Health Service (both Sydney, Australia). The available clinical characteristics of the patients, including age, sex, diagnosis, forced expiratory volume in $1 \mathrm{~s}$ and medical treatment prior to sampling, are shown in table 1.
All patients included in this study were diagnosed with asthma or COPD following the Global Initiative for Asthma (GINA) and Global Initiative for Chronic Obstructive Lung Disease (GOLD) standard definition.

ASMC were counted and seeded at a density of 100,000 cells $\cdot \mathrm{cm}^{2}$ in $175-\mathrm{cm}^{2}$ flasks for GAG extraction, and in $25-\mathrm{cm}^{2}$ flasks for mRNA extraction and for cell counting. ASMC were characterised by positive immunostaining for $\alpha$ smooth muscle cell actin, and calponin, as described previously [1]. ASMC were grown in Dulbecco modified Eagle medium supplemented with $5 \%$ fetal calf serum (FCS), $1 \%$ minimal essential medium vitamins, $8 \mathrm{mM}$ stabilised Lglutamine and $10 \mathrm{mM}$ HEPES buffer (GIBCO BRL; Life Technologies, Sydney, Australia). For all experiments, cells were used between passage four to nine; cells were grown until $80 \%$ confluence, and were serum deprived prior to

\section{TABLE 1 Clinical characteristics of patients}

\begin{tabular}{|c|c|c|c|c|}
\hline Diagnosis & Age yrs & Sex & FEV $1 \%$ pred & Therapy \\
\hline Healthy & 28 & M & 100 & None \\
\hline Healthy & 52 & M & NA & None \\
\hline Healthy & 61 & $\mathrm{~F}$ & 98 & None \\
\hline Healthy & 43 & M & NA & None \\
\hline Healthy & 36 & M & 97 & None \\
\hline Healthy & 57 & M & NA & None \\
\hline Healthy & 53 & M & 100 & None \\
\hline Healthy & 21 & $\mathrm{~F}$ & 100 & None \\
\hline Healthy & 24 & $\mathrm{~F}$ & NA & None \\
\hline Healthy & 25 & M & 100 & None \\
\hline Mean \pm SD & $37.5 \pm 18.7$ & & $99.16 \pm 1.33$ & \\
\hline COPD & 52 & M & 62 & Corticosteroids \\
\hline COPD & 57 & M & NA & $\beta_{2}$-agonists + corticosteroids \\
\hline COPD & 56 & M & 58 & $\beta_{2}$-agonists + corticosteroids \\
\hline $\begin{array}{l}\text { COPD/ } \\
\text { emphysema }\end{array}$ & 44 & $\mathrm{~F}$ & 56 & $\beta_{2}$-agonists + corticosteroids \\
\hline $\begin{array}{l}\text { COPD/ } \\
\text { emphysema }\end{array}$ & 48 & $\mathrm{~F}$ & 60 & $\beta_{2}$-agonists + corticosteroids \\
\hline $\begin{array}{l}\text { COPD/ } \\
\text { emphysema }\end{array}$ & 52 & M & NA & $\beta_{2}$-agonists + corticosteroids \\
\hline Mean \pm SD & $50.5 \pm 4.1$ & & $59 \pm 2.58$ & \\
\hline Asthma & 20 & $\mathrm{~F}$ & 75 & $\beta_{2}$-agonists + corticosteroids \\
\hline Asthma & 40 & M & 48 & $\beta_{2}$-agonists + corticosteroids \\
\hline Asthma & 43 & $\mathrm{~F}$ & 85 & None \\
\hline Asthma & 48 & M & NA & $\beta_{2}$-agonists + corticosteroids \\
\hline Asthma & 53 & $\mathrm{~F}$ & 63 & $\beta_{2}$-agonists + corticosteroids \\
\hline Asthma & 18 & $\mathrm{~F}$ & 82 & None \\
\hline Asthma & 33 & $\mathrm{~F}$ & NA & $\beta_{2}$-agonists + corticosteroids \\
\hline Asthma & 25 & M & 79 & None \\
\hline Asthma & 64 & M & NA & None \\
\hline Asthma & 52 & M & 58 & $\beta_{2}$-agonists + corticosteroids \\
\hline Asthma & 33 & $\mathrm{~F}$ & NA & $\beta_{2}$-agonists + corticosteroids \\
\hline Mean \pm SD & $39 \pm 23.7$ & & $70 \pm 13.5$ & \\
\hline
\end{tabular}

FEV1: forced expiratory volume in $1 \mathrm{~s}$; \% pred: \% predicted; COPD: chronic obstructive pulmonary disease; M: male; F: female; NA: not available. 
experiments for $24 \mathrm{~h}$ in medium containing $0.1 \%$ FCS. Unless otherwise stated, cells were routinely stimulated with 5\% FCS and incubated for $24 \mathrm{~h}$. Assays were performed on samples prior to stimulation ( $0 \mathrm{~h}$ of incubation) and on samples $12 \mathrm{~h}$ and $24 \mathrm{~h}$ after stimulation with 5\% FCS. Cells in the presence of $0.1 \%$ FCS are assumed to be under noninflammatory conditions, while stimulation with 5\% FCS is assumed to mimic an inflammatory condition. Comparisons described thereafter are either between ASMC of different origin, or between $0.1 \%$ and $5 \%$ FCS for a particular type of ASMC.

\section{$\left[{ }^{3} \mathrm{H}\right]$-glucosamine incorporation}

To measure de novo GAG synthesis, subconfluent ASMC were incubated with medium containing either $0.1 \%$ or $5 \%$ FCS in the presence of $\left[{ }^{3} \mathrm{H}\right]$-glucosamine $\left(0.5 \mu \mathrm{Ci} \cdot \mathrm{mL}^{-1}\right.$; Amersham Biosciences, Little Chalfont, UK) for $24 \mathrm{~h}$. Incorporation of $\left[{ }^{3} \mathrm{H}\right]$-glucosamine into GAG was measured as previously described [23]. In brief, culture medium was collected and cells were washed twice with ice-cold PBS and lysed with $200 \mu \mathrm{L}$ RIPA buffer (1\% nonidet P-40, 1\% sodium deoxycholate, $0.1 \%$ sodium dodecyl sulfate (SDS), $0.15 \mathrm{M} \mathrm{NaCl}, 0.01 \mathrm{M}$ sodium phosphate, $\mathrm{pH}$ 7.2). The cell layer (cells and deposited ECM) and cell culture medium were collected separately. Samples were digested with $0.1 \mathrm{KU}$ of pronase (Streptomyces griseus; Calbiochem, Lucerne, Switzerland) and total GAG were precipitated by adding a mixture of ethanol $(80 \%$ final concentration) containing $1.3 \%$ (weight/volume) sodium acetate (overnight at $4^{\circ} \mathrm{C}$ ). Following this, samples were centrifuged at $10,000 \times g$ for $15 \mathrm{~min}$. The pellets were dissolved in $0.5 \mathrm{M} \mathrm{NaOH}$ and total GAG synthesis was calculated on the basis of $\left[{ }^{3} \mathrm{H}\right]$-glucosamine incorporated into GAG.

\section{Isolation, purification, fractionation and characterisation of GAG}

Cell culture media $(20 \mathrm{~mL})$ were collected separately from the cell layers, which were washed twice with $10 \mathrm{~mL}$ of ice-cold PBS and harvested by scraping. GAG were isolated and purified from the culture media and the cell layers, as previously described [24]. In brief, lipids were extracted with four volumes of chloroform:methanol (1:2). Organic solvents were removed by centrifugation $\left(3,200 \times g, 20 \mathrm{~min}, 4^{\circ} \mathrm{C}\right)$ and the pellet was washed with $10 \mathrm{~mL}$ of ethanol, centrifuged $\left(3,200 \times g, 20 \mathrm{~min}, 4^{\circ} \mathrm{C}\right)$ and dried $\left(4 \mathrm{~h}, 40^{\circ} \mathrm{C}\right)$. The pellet was

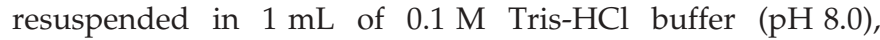
containing $1 \mathrm{mM} \mathrm{CaCl}$ and the protein was digested with $0.1 \mathrm{KU}$ of pronase (S. griseus; Calbiochem) $\left(72 \mathrm{~h}, 60^{\circ} \mathrm{C}\right)$ by adding equal amounts of pronase at $24-\mathrm{h}$ intervals. The pronase solution was pre-heated $\left(30 \mathrm{~min}, 60^{\circ} \mathrm{C}\right)$ to eliminate any glycosidase activity. DNA digestion was accomplished by incubation with $400 \mathrm{KU}$ of DNase I (EC 3.1.21.1; Calbiochem) $\left(16 \mathrm{~h}, 37^{\circ} \mathrm{C}\right)$. After adjustment of the $\mathrm{CaCl}_{2}$ concentration to $1 \mathrm{mM}$, the reaction was stopped by $0.1 \mathrm{KU}$ of pronase $\left(60^{\circ} \mathrm{C}\right.$, $24 \mathrm{~h})$. The samples were then titrated with $10 \mathrm{mM} \mathrm{NaOH}$ to $\mathrm{pH} 10.0-11.0$, and incubated $\left(16 \mathrm{~h}, 45^{\circ} \mathrm{C}\right)$ in the presence of $1 \mathrm{M} \mathrm{NaBH}_{4}$. Samples were neutralised with $50 \%$ (v/v) acetic acid and the extracted GAG were precipitated by the addition of four volumes of ethanol in the presence of 0.1 volume of $3 \mathrm{M}$ $\mathrm{CH}_{3} \mathrm{COONa}$ (overnight, $4^{\circ} \mathrm{C}$ ). GAG were recovered by centrifugation $(2,000 \times g, 20 \mathrm{~min})$ and the pellets were dissolved in double-distilled $\mathrm{H}_{2} \mathrm{O}$ and stored at $4{ }^{\circ} \mathrm{C}$. Colorimetric determination of uronic acids was performed according to the study by BITTER and MUIR [25].

\section{Fractionation of total GAG}

Fractionation of GAG was achieved by electrophoresis on cellulose acetate membranes as described previously [24]. In brief, $2 \mu \mathrm{L}$ of the GAG solution, containing $4 \mu \mathrm{g}$ of uronic acid, was placed at the origin ( $10 \mathrm{~mm}$ from the cathode side) of a cellulose acetate strip. Electrophoresis was carried out in $100 \mathrm{mM}$ pyridine $/ 470 \mathrm{mM}$ formic acid ( $\mathrm{pH} 3.0$ ) at $7 \mathrm{~mA}$ constant current (70 min, room temperature). After electrophoresis, cellulose acetate membranes were stained with $0.2 \%$ Alcian blue $(\mathrm{w} / \mathrm{v})$, in $0.1 \%$ acetic acid $(\mathrm{v} / \mathrm{v})$, for $10 \mathrm{~min}$ and washed with $0.1 \%$ acetic acid $(\mathrm{v} / \mathrm{v})$ for $20 \mathrm{~min}$. The intensity of the staining was quantified by a computer-assisted image analysis program (Eastman Kodak, Rochester, NY, USA).

\section{Treatment of the purified glycans with GAG-degrading enzymes}

Speed-vacuum dried GAG (5 $\mu$ g uronic acid) were incubated in a final volume of $15 \mu \mathrm{L}$ of one of the following. 1) Heparinase: samples dissolved in $100 \mathrm{mM}$ Tris- $\mathrm{HCl}$ buffer ( $\mathrm{pH} 7.0$ ) containing $3 \mathrm{mM} \mathrm{CaCl} 2$ and incubated $\left(15 \mathrm{~h}, 30^{\circ} \mathrm{C}\right.$ ) with $4 \times 10^{4} \mathrm{U}$ heparin lyase I (EC 4.2.2.7, Flavobacterium heparinum; Seikagaku, Tokyo, Japan). 2) Heparitinase: samples dissolved as previously described were incubated $\left(16 \mathrm{~h}, 43^{\circ} \mathrm{C}\right)$ with $4 \times 10^{-4} \mathrm{U}$ heparan sulfate lyase (heparitinase: EC 4.2.2.8, F. heparinum; Seikagaku). 3) Chondroitinase ABC: samples dissolved in $100 \mathrm{mM}$ Tris- $\mathrm{HCl}$ buffer ( $\mathrm{pH} \mathrm{8.0)} \mathrm{containing}$ $50 \mathrm{mM}$ sodium acetate were incubated $\left(16 \mathrm{~h}, 37^{\circ} \mathrm{C}\right)$ with $2 \times 10^{4} \mathrm{U}$ chondroitin ABC lyase (EC 4.2.2.4, Proteus vulgaris; Sigma-Aldrich Chemie, Steinheim, Germany). 4) Chondroitinase B: samples dissolved in $100 \mathrm{mM}$ Tris- $\mathrm{HCl}$ buffer ( $\mathrm{pH} 7.4)$ were incubated $\left(16 \mathrm{~h}, 37^{\circ} \mathrm{C}\right)$ with $0.1 \mathrm{U}$ chondroitin B lyase (F. heparinum; Sigma-Aldrich Chemie). 5) Keratanase: samples dissolved in $50 \mathrm{mM}$ Tris- $\mathrm{HCl}$ buffer $(\mathrm{pH} 7.4)$ were incubated $\left(16 \mathrm{~h}, 37^{\circ} \mathrm{C}\right)$ with $0.05 \mathrm{U}$ keratan sulfate endo- $\beta$-D-galactosidase (EC 3.2.10.3, Pseudomonas species; Sigma-Aldrich Chemie). 6) Hyaluronidase: samples dissolved in $20 \mathrm{mM}$ sodium acetate, buffered with acetic acid to $\mathrm{pH} 5.0$, were incubated $\left(14 \mathrm{~h}, 60^{\circ} \mathrm{C}\right)$ with $4 \mathrm{U}$ hyaluronate lyase (EC 4.2.2.1, Streptomyces hyalurolyticus; Sigma-Aldrich Chemie). Incubation times and enzyme concentrations were as required for complete degradation of standard substrates, as previously described [26]. Substrates incubated separately with their respective buffers served as controls. Digestion was evaluated by electrophoresis on cellulose acetate membranes and quantified by the computer-assisted image analysis program of Eastman Kodak.

\section{Measurements of HA}

Net amount of HA secreted by primary ASMC

Cells were grown in 24-well plates, washed twice with culture medium to remove HA accumulated during cell growth and incubated for $24 \mathrm{~h}$. At the end of incubation time, aliquots of cell culture medium were collected and tested for the quantity of HA by ELISA (Corgenix, Westminster, CO, USA). Briefly, ELISA plates coated with HA binding protein were incubated with samples or standards ( $1 \mathrm{~h}$, room temperature) in duplicates, washed five times with washing buffer, incubated with a solution containing horseradish peroxidase-conjugated 
HA-binding protein (30 min, room temperature), washed again five times, and incubated with $100 \mu \mathrm{L}$ of the substrate solution. After $30 \mathrm{~min}$, the reaction was stopped by adding an equal amount of sulfuric acid $(0.36 \mathrm{~N})$, and the optical density was measured at $450 \mathrm{~nm}$ (630-nm reference).

\section{Relative amount of HA in total GAG}

Total GAG was isolated and purified from the cell culture medium and the cell layers, as described previously, and the relative amount of $\mathrm{HA}$ was measured in aliquots containing $0.1 \mu \mathrm{g}$ of uronic acids by ELISA (Corgenix, Peterborough, UK), as described previously.

\section{Polyacrylamide gel electrophoresis}

Total GAG (4 $\mu \mathrm{g}$ uronic acids) isolated and purified from the culture medium or the cell layers of ASMC was analysed on $4 \%$ polyacrylamide gels, as previously described [26]. HA of $225 \mathrm{kDa}$ and CS of 29 and $57 \mathrm{kDa}$ were used as molecular weight markers. The molecular mass of the markers was previously determined by analytical ultracentrifugation [27]. Gels were stained with a solution of $0.5 \%(\mathrm{w} / \mathrm{v})$ Alcian blue, dissolved in $25 \%(\mathrm{v} / \mathrm{v})$ isopropyl alcohol and $1 \%(\mathrm{v} / \mathrm{v})$ acetic acid, for $12 \mathrm{~h}$. The same solution without the dye was used for destaining.

\section{RT-PCR}

RNA was extracted from cells using the RNeasy (Qiagen, Hilden, Germany). Total RNA was subjected to reverse transcription using moloney murine leukaemia virus-reverse transferase (Invitrogen $\mathrm{GmbH}$, Life Technologies, Karlsruhe, Germany). $5 \mu \mathrm{L}$ of the reaction mixture were subjected to PCR amplification in $50 \mu \mathrm{L}$ reaction volume, containing 25 pmol of relevant primers, $200 \mu \mathrm{M}$ deoxyribonucleotide triphosphate
(Invitrogen $\mathrm{GmbH}$, Life Technologies), $2 \mathrm{mM} \mathrm{MgCl}_{2}$ and one unit of Taq DNA polymerase in $1 \times$ Taq DNA polymerase buffer (Promega, Madison, WI, USA), on a PTC-100 Thermal Controller (MJ Research Inc., Watertown, MA, USA). All primer sequences and the PCR conditions are listed in table 2. PCR products were analysed on a $2 \%(\mathrm{w} / \mathrm{v})$ agrose gel. DNA bands were visualised in ethidium bromide-stained gels under UV light and quantified on the basis of $\beta$-actin mRNA expression, which was amplified under nonsaturating conditions using the computer-assisted image analysis program of Eastman Kodak.

\section{Western blot analysis}

Total protein extracts were prepared from $80 \%$ confluent ASMC. $10 \mu \mathrm{g}$ of proteins were dissolved in Laemmli buffer, denatured $\left(95^{\circ} \mathrm{C}, 5 \mathrm{~min}\right)$, chilled on ice ( $\left.5 \mathrm{~min}\right)$, centrifuged $(13,000 \times g, 50 \mathrm{~s})$, and applied to electrophoresis on $4-15 \%$ SDSPAGE. Proteins were transferred on to polyvinylidene fluoride membranes (Bio-Rad Laboratories, Hercules, CA, USA) by overnight transfer at $50^{\circ} \mathrm{C}$, which was confirmed by staining with Coomasie Blue. The membranes were then washed three times with PBS, blocked with 5\% skimmed milk in PBS $\left(4^{\circ} \mathrm{C}\right.$, overnight), and incubated with one of the primary antibodies (CD44: sc-59909, RHAMM: sc-16170, HYAL1: sc-101340, HAS1: sc-23145, HAS2: sc-66916; all from Santa Cruz Biotechnology Inc., Santa Cruz, CA, USA) overnight at $4^{\circ} \mathrm{C}$. The membranes were then washed three times ( 5 min per time) with blocking buffer and incubated with a secondary antibody at room temperature for $90 \mathrm{~min}$ (CD44: sc-2005; RHAMM: sc-2020; Hyal-1: sc-2005; HAS1: sc-2020; HAS2: sc-2004; all from Santa Cruz Biotechnology Inc.). Before bands were visualised the membranes were washed three times with PBS and then soaked in SuperSignal West Pico Chemilluminescent Substrate

TABLE 2 Primer sequences

\begin{tabular}{|c|c|c|c|c|}
\hline Primers & Sequences & Cycles & Annealing temperature ${ }^{\circ} \mathrm{C}$ & Product size bp \\
\hline \multirow[t]{2}{*}{ Has1 } & For: GCGATACTGGGTAGCCTTCA & 30 & 57 & 131 \\
\hline & Rev: GGTTGTACCAGGCCTCAAGA & & & \\
\hline \multirow[t]{2}{*}{ Has2 } & For: ACAGACAGGCTGAGGACGAC & 28 & 57 & 126 \\
\hline & Rev: GCTGTGATTCCAAGGAGGAG & & & \\
\hline \multirow[t]{2}{*}{ Has3 } & For: GTCATGTACACGGCCTTCAA & 35 & 59 & 130 \\
\hline & Rev: CCTACTTGGGGATCCTCCTC & & & \\
\hline \multirow[t]{2}{*}{ Hyal1 } & For: GTGCTGCCCTATGTCCAGAT & 35 & 59 & 132 \\
\hline & Rev: ATTTTCCCAGCTCACCCAGA & & & \\
\hline \multirow[t]{2}{*}{ Hyal2 } & For: TCTACCATTGGCGAGAGTG & 27 & 57 & 119 \\
\hline & Rev: AGCAGCCGTGTCAGGTAAT & & & \\
\hline \multirow[t]{2}{*}{ Hyal3 } & For: GATCTGGGAGGTTCCTGTCC & 30 & 57 & 110 \\
\hline & Rev: AGAGCTGGAGAGGCTCAGGT & & & \\
\hline \multirow[t]{2}{*}{ CD44 } & For: ATGGACAAGTTTTGGTGGCA & 22 & 57 & 1546 \\
\hline & Rev: GTCCCAGCTCCCTGTAATGG & & & \\
\hline \multirow[t]{2}{*}{ Rhamm } & For: GTCACCTTCAGTTTCTGGAGCTGG & 32 & 55 & 2265 \\
\hline & Rev: GCAACATCAATAACAACAAGACGA & & & \\
\hline \multirow[t]{2}{*}{$\beta$-actin } & For: ACACTGTGCCCATCTACGAGG & 20 & 57 & 621 \\
\hline & Rev: AGGGGCCGGACTCGTCATACT & & & \\
\hline
\end{tabular}

Has: hyaluronic acid synthase; Hyal: hyaluronidase; Rhamm: receptor for hyaluronic acid-mediated motility 

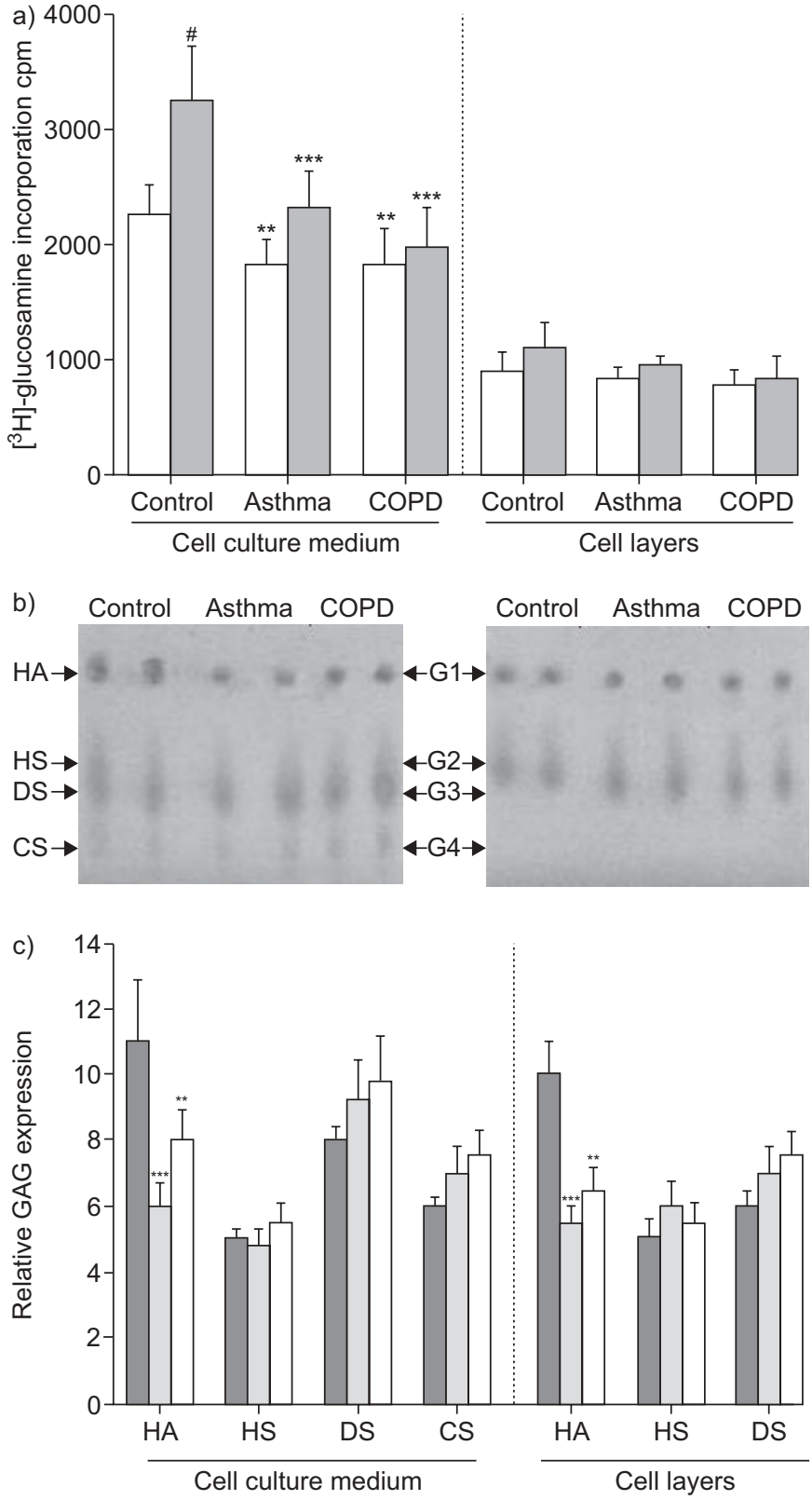

FIGURE 1. Total glycosaminoglycan (GAG) secretion and deposition by primary airway smooth muscle cells (ASMC) from control, asthmatic and chronic obstructive pulmonary disease (COPD) patients. a) Subconfluent (80\%) primary ASMC were incubated with $0.1 \%(\square)$ or $5 \%$ ( $\square$ ) fetal calf serum (FCS) in the presence of $\left[{ }^{3} \mathrm{H}\right]$-glucosamine $\left(0.5 \mu \mathrm{Ci} \cdot \mathrm{mL}^{-1}\right)$ for $24 \mathrm{~h}$. Total $\mathrm{GAG}$ secretion and deposition in the extracellular matrix were determined as counts per minute. Experiments were performed in triplicate for each patient. Error bars represent mean \pm SEM of 10 healthy donors, 11 patients with asthma and six patients with COPD. ${ }^{\#}$ : $p<0.001$ compared with $0.1 \%$ FCS; $* *$ : $p<0.01$ compared with control; $* * *$ : $p<0.001$ compared with control. b) Representative analysis of the electrophoretic mobility on cellulose acetate membranes of GAG (G1 to G4) isolated and purified from primary ASMC of two healthy donors, two asthma patients and two COPD patients. Total GAG was isolated and purified $24 \mathrm{~h}$ after stimulation with $5 \%$ FCS from cell culture medium (left-hand gel) or cell layers (right-hand gel). Migration of commercially available markers is indicated by arrows on the left. HA: hyaluronic acid; HS: heparan sulfate; DS: dermatan sulfate; CS: chondroitin sulfate. C) Quantitation of Alcian blue intensity using a computer-assisted analysis program. Error bars represent the mean \pm SEM of triplicate determinations for each patient. **: (cat 34077; Thomas Fisher Scientific Inc., Rockford, IL, USA). To visualise the protein bands the membranes were exposed to Bio-Max-ray films (Eastman Kodak).

\section{Protein determination}

The protein content was determined in aliquots of cell culture medium by standard Bradford assay (Bio-Rad, Glattbrugg, Switzerland) using bovine serum albumin (Sigma-Aldrich Chemie) as standard.

\section{Statistical analysis}

The computer software SPSS 16.0 (SPSS Inc., Chicago, IL, USA) was used for all statistical calculations and analyses. Normal distribution of data was checked using Kolmogorov-Smirnov analysis. All parametric data were analysed with ANOVA for repeated measurements. If significant, ANOVA was followed by post hoc multiple comparisons between the control and other groups by Dunett's test. Nonparametric data were analysed with the Kruskal-Wallis test while Friedman's test was used for related samples. Two-tailed levels of significance were used in all statistical calculations. Reproducibility of measurements was checked with the coefficient of variation factor. All data are expressed as mean \pm SEM of the mean. Difference was considered to be statistically significant at $\mathrm{p}<0.05, \mathrm{p}<0.01$ and $\mathrm{p}<0.001$.

\section{RESULTS}

\section{Characterisation of ASMC}

Under light microscopy, ASMC from controls, asthmatics and COPD patients appeared to be spindle shaped, with central oval nuclei containing prominent nucleoli, and displayed the typical "hill and valley" proliferation pattern in culture (data not shown). All cells showed uniform staining for both the smooth muscle-specific contractile proteins $\alpha$-smooth muscle actin and calponin, as previously described [1], indicating that these cells were ASMC.

\section{Total GAG secretion and deposition by ASMC}

Measurements of total GAG synthesis by $\left[{ }^{3} \mathrm{H}\right]$-glucosamine incorporation revealed that under noninflammatory conditions (cells in the presence of $0.1 \%$ FCS) there were no significant differences in the secretion and deposition of total GAG by ASMC between controls and patients with asthma or COPD (fig. 1a). However, under inflammatory conditions (cells stimulated with 5\% FCS), secretion of total GAG was increased in all three groups (fig. 1a) but this effect was only significant for secreted GAG by control ASMC $(2,150 \pm 250$ counts per min for $0.1 \%$ FCS versus $3,151 \pm 625 \mathrm{cpm}$ for $5 \%$ FCS, $\mathrm{p}<0.05$; fig. 1a).

Furthermore, when stimulated with 5\% FCS, ASMC from patients with asthma or COPD secreted significantly less GAG than ASMC from controls $(3,240 \pm 475,2,310 \pm 315$ and $1,980 \pm 325$ for controls, asthma and COPD, respectively; $\mathrm{p}<0.01$ for control versus asthma and $\mathrm{p}<0.05$ for control versus COPD) (fig. 1a).

$p<0.01 ; * * *: p<0.001$. The statistical differences indicated are between controls and asthma or COPD in cell culture medium and cell layers, respectively. control; 1 : asthma; $\square$ : COPD. 


\begin{tabular}{|c|c|c|c|c|c|c|c|}
\hline \multirow{2}{*}{$\begin{array}{l}\text { TABLE } 3 \\
\text { Substrate }\end{array}$} & \multicolumn{7}{|c|}{$\begin{array}{l}\text { Enzymatic treatment with glycosaminoglycan (GAG) degrading enzymes of total GAG isolated and purified from } \\
\text { orimary airway smooth muscle cells }{ }^{\#}\end{array}$} \\
\hline & GAG population & Chondroitinase $A B C$ & Chondroitinase B & Hyaluronidase & Heparinase & Heparitinase & Keratanase \\
\hline \multirow[t]{3}{*}{ Control cell layer } & G1 & $(-)$ & $(-)$ & $(+)$ & $(-)$ & $(-)$ & $(-)$ \\
\hline & G2 & $(-)$ & $(-)$ & $(-)$ & $(-)$ & $(+)$ & $(-)$ \\
\hline & G3 & $(+)$ & $(+)$ & $(-)$ & $(-)$ & $(-)$ & $(-)$ \\
\hline \multirow{3}{*}{ Control medium } & G2 & $(-)$ & $(-)$ & $(-)$ & $(-)$ & $(+)$ & $(-)$ \\
\hline & G3 & $(+)$ & $(+)$ & $(-)$ & $(-)$ & $(-)$ & $(-)$ \\
\hline & G4 & $(+)$ & $(-)$ & $(-)$ & $(-)$ & $(-)$ & $(-)$ \\
\hline \multirow[t]{3}{*}{ Asthma cell layer } & G1 & $(-)$ & $(-)$ & $(+)$ & $(-)$ & $(-)$ & $(-)$ \\
\hline & G2 & $(-)$ & $(-)$ & $(-)$ & $(-)$ & $(+)$ & $(-)$ \\
\hline & G3 & $(+)$ & $(+)$ & $(-)$ & $(-)$ & $(-)$ & $(-)$ \\
\hline \multirow[t]{3}{*}{ COPD cell layer } & G1 & $(-)$ & $(-)$ & $(+)$ & $(-)$ & $(-)$ & $(-)$ \\
\hline & G2 & $(-)$ & $(-)$ & $(-)$ & $(-)$ & $(+)$ & $(-)$ \\
\hline & G3 & $(+)$ & $(+)$ & $(-)$ & $(-)$ & $(-)$ & $(-)$ \\
\hline \multirow[t]{4}{*}{ COPD medium } & G1 & $(-)$ & $(-)$ & $(+)$ & $(-)$ & $(-)$ & $(-)$ \\
\hline & G2 & $(-)$ & $(-)$ & $(-)$ & $(-)$ & $(+)$ & $(-)$ \\
\hline & G3 & $(+)$ & $(+)$ & $(-)$ & $(-)$ & $(-)$ & $(-)$ \\
\hline & G4 & $(+)$ & $(-)$ & $(-)$ & $(-)$ & $(-)$ & $(-)$ \\
\hline CSA & & $(+)$ & $(-)$ & $(-)$ & $(-)$ & $(-)$ & $(-)$ \\
\hline DS & & $(+)$ & $(+)$ & $(-)$ & $(-)$ & $(-)$ & $(-)$ \\
\hline csc & & $(+)$ & $(-)$ & $(-)$ & $(-)$ & $(-)$ & $(-)$ \\
\hline
\end{tabular}

CSA: chondroitin sulfate A; DS: dermatan sulfate; CSC: chondroitin sulfate C; H: heparin; HA: hyaluronic acid; HS: heparan sulfate; KS: keratan sulfate; -: no detectable

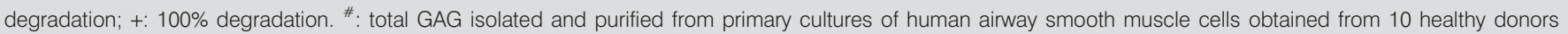
(controls), 11 patients with asthma and six COPD patients treated with GAG degrading enzymes. The digestion was monitored by electrophoresis on cellulose acetate membranes. ": obtained following cellulose acetate electrophoresis, the numbers correspond to those in figure $1 \mathrm{~b}$.

\section{Identification of GAG in ASMC}

Electrophoresis on cellulose acetate membranes of $4 \mu \mathrm{g}$ of uronic acids of total GAG isolated from the cell culture medium of control ASMC, $24 \mathrm{~h}$ after stimulation with 5\% FCS, resulted in four distinct GAG populations, assigned as G1, G2, G3 and G4 (fig. 1b), which migrated with the same mobility as HA, HS, DS and CS, respectively. Enzymatic treatment with specific GAG-degrading enzymes (table 3) confirmed that G1 is HA, G2 is HS, G3 is DS and G4 is CSA and/or CSC. The same GAG were also identified in the cell culture medium of ASMC obtained from asthma and COPD patients (fig. 1b) indicating that there are no qualitative differences in the nature of total GAG secreted by ASMC from controls and patients with asthma or COPD. However, quantitation of the Alcian blue staining with a computer-assisted image analysis program revealed that HA secretion was significantly decreased in the cell culture medium of ASMC from patients with asthma and COPD compared with controls (fig. 1c).
We further analysed the GAG deposited in the cell layers of ASMC from healthy lung tissue and patients with asthma or COPD. Three distinct GAG populations were identified, which were characterised by enzymatic treatment as HA, HS and DS (fig. 1b, table 3). Quantitation of the intensity of the Alcian blue staining indicated that the amount of HA which was deposited in the cell layers of ASMC was significantly decreased in asthma and COPD compared with controls (fig. 1c).

\section{Reduced secretion of HA by ASMC from patients with asthma and COPD}

Since HA was the most abundant GAG secreted or deposited by primary ASMC from all three groups, and since there were indications from the Alcian blue staining of cellulose acetate membranes that HA was decreased in asthma and COPD, we further measured the net amount of HA secreted by ASMC after 12 and $24 \mathrm{~h}$ of incubation by ELISA. Compared with 

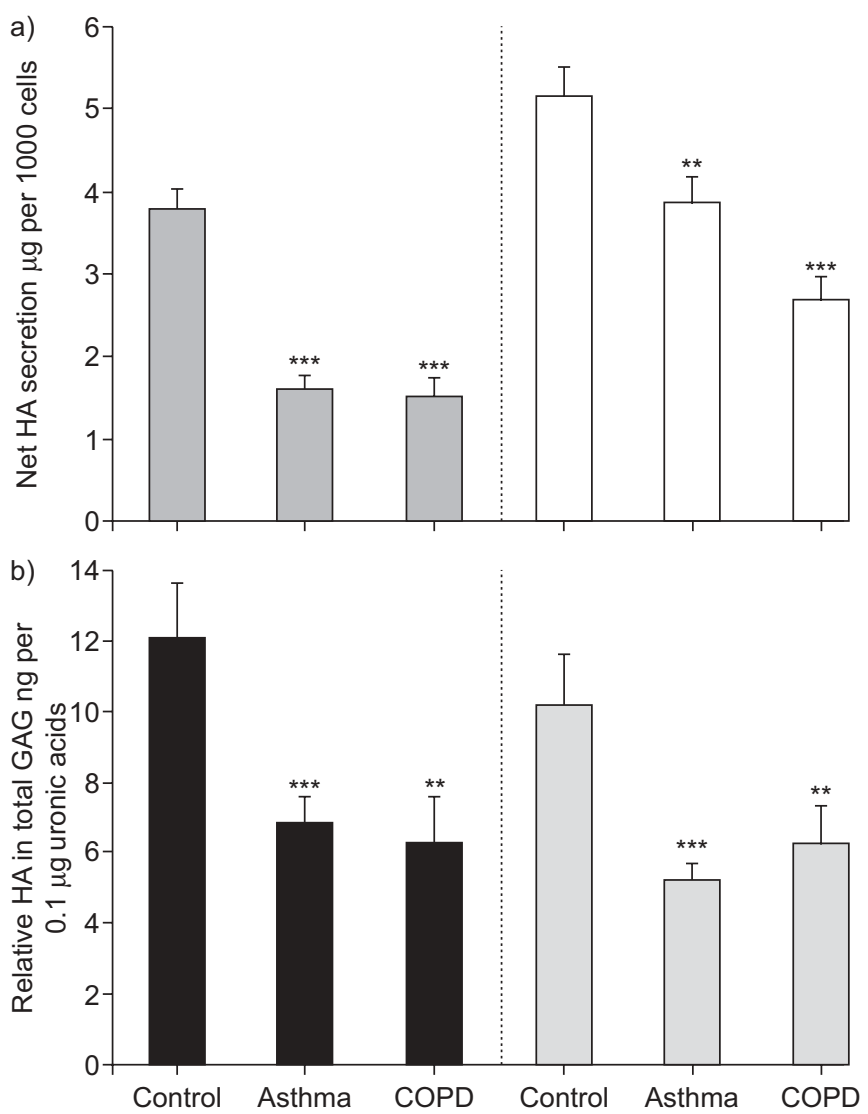

FIGURE 2. Disease-specific secretion and relative amount of hyaluronic acid (HA) by human airway smooth muscle cells. a) The amount of secreted HA was measured using ELISA in aliquots of cell culture medium after $12 \mathrm{~h} \mathrm{( \square )}$ and $24 \mathrm{~h}$ ( $\square$ ). b) The relative amount of HA was determined by ELISA in aliquots of total glycosaminoglycan (GAG) containing $0.1 \mu \mathrm{g}$ of uronic acids in cell culture medium $(\square)$ and cell layers $(\square)$. Determinations were performed in triplicate for each patient. Error bars represent mean \pm SEM of 10 healthy donors, 11 patients with asthma and six patients with chronic obstructive pulmonary disease (COPD). **: $p<0.01 ; * * *: p<0.001$. Statistical differences indicated are between controls and asthma or COPD

controls, ASMC from asthma or COPD patients secreted significantly lower amounts of $\mathrm{HA}$ after $12 \mathrm{~h}(3.7 \pm 0.25$, $1.6 \pm 0.17$ and $1.5 \pm 0.25 \mu \mathrm{g} \mathrm{HA} \cdot 1,000$ cells $^{-1}$ for controls, asthma and COPD, respectively; $\mathrm{p}<0.01$ ) (fig. $2 \mathrm{a}$ ) and $24 \mathrm{~h}$ of incubation $\left(5.1 \pm 0.35,3.8 \pm 0.30\right.$ and $2.7 \pm 0.25 \mu \mathrm{g} \mathrm{HA} \cdot 1000$ cells $^{-1}$ for controls, asthma and COPD, respectively; $\mathrm{p}<0.02$ and $\mathrm{p}<0.01$ for asthma and COPD, respectively) (fig. 2a).

The relative content of $\mathrm{HA}$ in $0.1 \mu \mathrm{g}$ of uronic acid of total secreted or deposited GAG was also measured using ELISA. We observed that the amount of HA measured in secreted GAG was significantly lower in asthma $(6.32 \pm 0.8 \mathrm{ng}$ per $0.1 \mu \mathrm{g}$ of uronic acids, $\mathrm{p}<0.01)$ and COPD $(7.57 \pm 1.8 \mathrm{ng}$ per $0.1 \mu \mathrm{g}$ of uronic acids, $\mathrm{p}<0.02)$ as compared to control $(11.77 \pm 1.5 \mathrm{ng}$ per $0.1 \mu \mathrm{g}$ of uronic acids) (fig. 2b). Furthermore, the amount of HA that was measured in GAG deposited in the cell layers was significantly lower in asthma $(4.55 \pm 0.6 \mathrm{ng}$ per $0.1 \mu \mathrm{g}$ of uronic acids, $\mathrm{p}<0.01)$ and COPD $(6.12 \pm 1.4 \mathrm{ng}$ per $0.1 \mu \mathrm{g}$ of uronic acids, $\mathrm{p}<0.02)$, as compared to control (9.72 $\pm 1.2 \mathrm{ng}$ per $0.1 \mu \mathrm{g}$ of uronic acids) (fig. $2 \mathrm{~b}$ ).

\section{Gene and protein expression of HAS1 and HAS2 decreases whereas expression of HYAL1 increases in asthma and COPD}

Since HA secretion and deposition was decreased in asthma and COPD, we sought to further investigate the expression of HA metabolising enzymes by RT-PCR. As shown in figure 3a, ASMC of different origin express Has1, Has2 and Has3. Quantitation of the PCR results by an image analysis program revealed that the expression of Has1 was significantly decreased in ASMC from asthma patients at 0,12 or $24 \mathrm{~h}$ $(p<0.05)$ or from COPD patients after $24 \mathrm{~h}$ of incubation $(\mathrm{p}<0.05)$, as compared to controls (fig. 3b). Has2 mRNA expression was also significantly decreased in ASMC from asthma or COPD patients $(\mathrm{p}<0.05)$, as compared to controls (fig. 3c). There were no significant differences for Has3 expression between ASMC of different origin (fig. 3d). Immunoblot experiments using antibodies against HAS1 and HAS2 showed that protein expression of both enzymes was reduced in asthma and COPD as compared to controls (fig. 3e), confirming the results obtained from the RT-PCR analysis.

Hyal1, Hyal2 and Hyal3 were also expressed in ASMC from all three groups (fig. 4a). Quantitation of the PCR results revealed that the expression of Hyal1 (fig. 4b) was increased in ASMC from asthma at $24 \mathrm{~h}(\mathrm{p}<0.05)$ and from COPD patients at 0,12 and $24 \mathrm{~h}(\mathrm{p}<0.01)$, as compared to controls. There were no significant differences in the expression of Hyal2 (fig. 4c) or Hyal3 (fig. 4d) between ASMC of different origin. Immunoblot experiments using antibodies against HYAL1 showed that protein expression of this enzyme was induced in asthma and COPD as compared to controls (fig. 4e), confirming the results obtained from the RT-PCR analysis.

\section{HA in asthma and COPD has a lower molecular mass than controls}

We further investigated if the differential expression of HYAL1, HAS1 and HAS2 in ASMC from asthma or COPD patients resulted in HA of different molecular mass, as compared with controls. We performed PAGE analysis of $4 \mu \mathrm{g}$ of the total GAG isolated and purified from ASMC of different origin and compared to GAG of known molecular mass (fig. 5). The migration of $\mathrm{HA}$ was identified after treatment of the samples with hyaluronidase prior to PAGE (data not shown). We found that HA isolated from the cell layers of control ASMC after stimulation with 5\% FCS for $24 \mathrm{~h}$, migrated with an average molecular mass $>700 \mathrm{kDa}$, whereas HA of asthma and COPD ASMC exhibited a lower average molecular mass of $250 \mathrm{kDa}$ (fig. 5). Similar results were obtained for HA isolated from the cell culture medium. These results indicate that asthma and COPD are associated with the presence of $\mathrm{HA}$ in the lung which has a lower molecular mass than HA in healthy lungs.

\section{Disease-specific gene and protein expression of $H A$ receptors CD44 and RHAMM by ASMC}

Furthermore, we investigated the transcription of HA receptors by ASMC. RT-PCR analysis revealed that CD44 was constitutively expressed by ASMC of different origin (fig. 6c). Quantitation of the PCR results revealed that the expression of CD44 was reduced in cells of asthma patients and this result was statistically significant after $24 \mathrm{~h}(\mathrm{p}<0.01)$ of treatment 

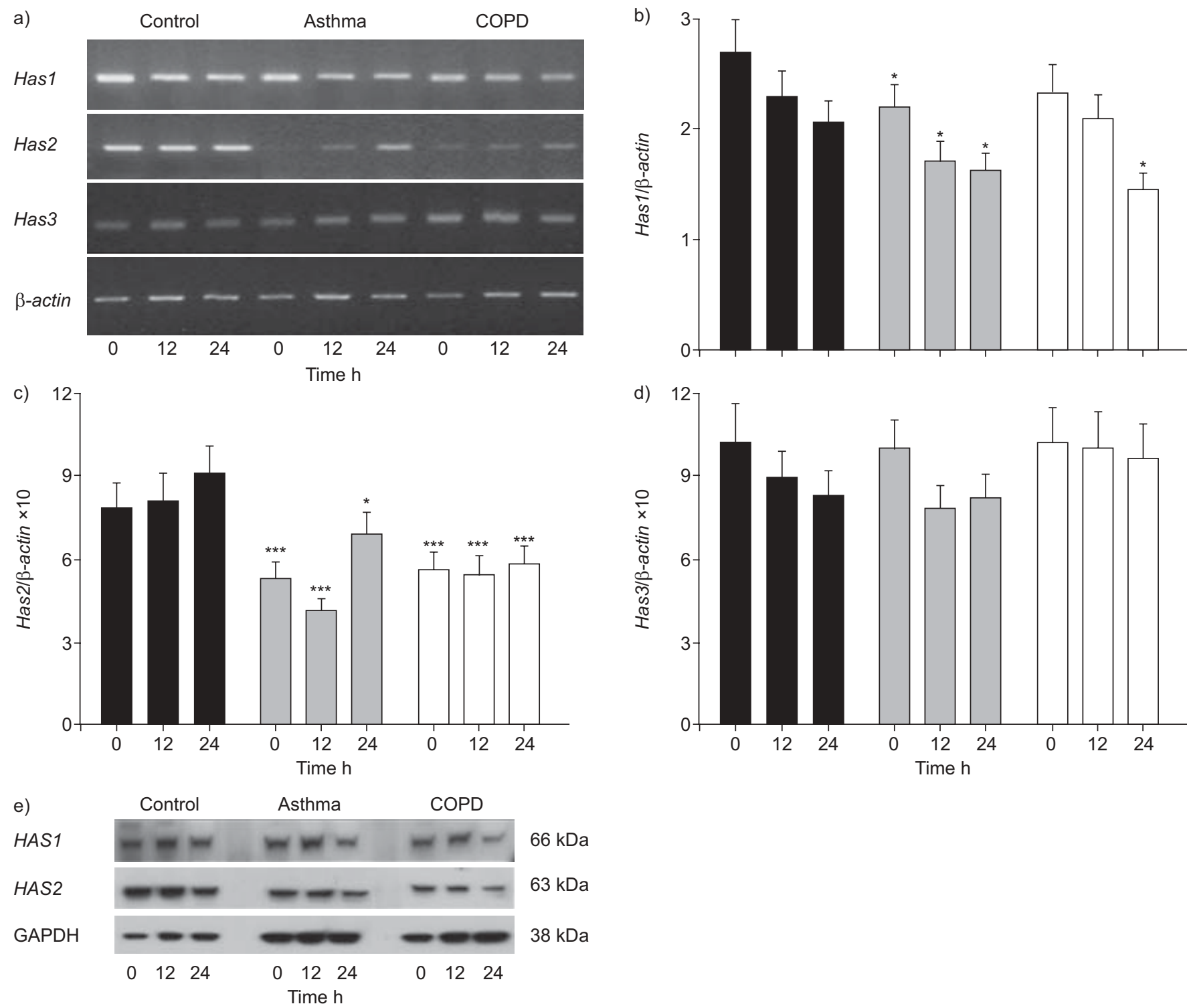

FIGURE 3. Disease-specific expression of hyaluronic acid synthases (Has) by airway smooth muscle cells (ASMC). a) Representative mRNA expression of Has1, Has2, Has3 and $\beta$-actin in ASMC stimulated by $5 \%$ fetal calf serum over $24 \mathrm{~h}$. Densitometric ratios of b) Has $1 / \beta$-actin, c) Has2/ $\beta$-actin and d) Has $3 / \beta$-actin. As the expression was

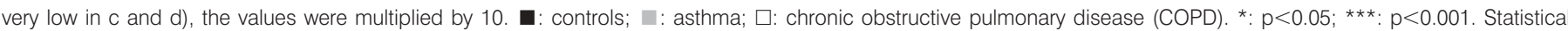
differences indicated are between controls and asthma or COPD at each time-point. Error bars represent the mean \pm SEM of triplicate determinations of the Has/ $\beta$-actin ratio calculated from ASMC established from 10 healthy donors, 11 asthma and six COPD patients. e) Representative HAS1 and HAS2 protein levels investigated by Western blotting. Glyceraldehyde-3-phosphate dehydrogenase (GAPDH) served as a loading control.

with 5\% FCS ( $\mathrm{p}<0.05$, fig. 6a). In ASMC from COPD patients, the CD44 mRNA level was significantly reduced after $12 \mathrm{~h}$ $(p<0.02)$ and $24 \mathrm{~h}$ of treatment with 5\% FCS (fig. 6a). Immunoblot experiments confirmed the results obtained from the RT-PCR analysis. As shown in figure $6 \mathrm{~d}, \mathrm{CD} 44$ protein expression was reduced in asthma and COPD compared with controls.

RT-PCR analysis for the mRNA encoding for Rhamm revealed that it was expressed only by control ASMC (fig. 6c). The expression of Rhamm in control ASMC significantly increased within $24 \mathrm{~h}$ of treatment with $5 \%$ FCS by almost five-fold $(\mathrm{p}<0.01$; fig. $6 \mathrm{~b})$. Interestingly, ASMC of asthma or COPD patients did not express Rhamm at any time-point investigated (fig. 6c). These results were also confirmed by immunoblot experiments. As shown in figure 6d, RHAMM protein was not expressed in ASMC obtained from patients with asthma and COPD.

\section{DISCUSSION}

The pathogenesis of asthma and COPD includes chronic inflammation of the airways and airway remodelling. Major features of the remodelling processes include: fibrosis in the sub-epithelial regions and the nearby interstitial tissue of the airways; myocyte hypertrophy and hyperplasia; myofibroblast 
a)
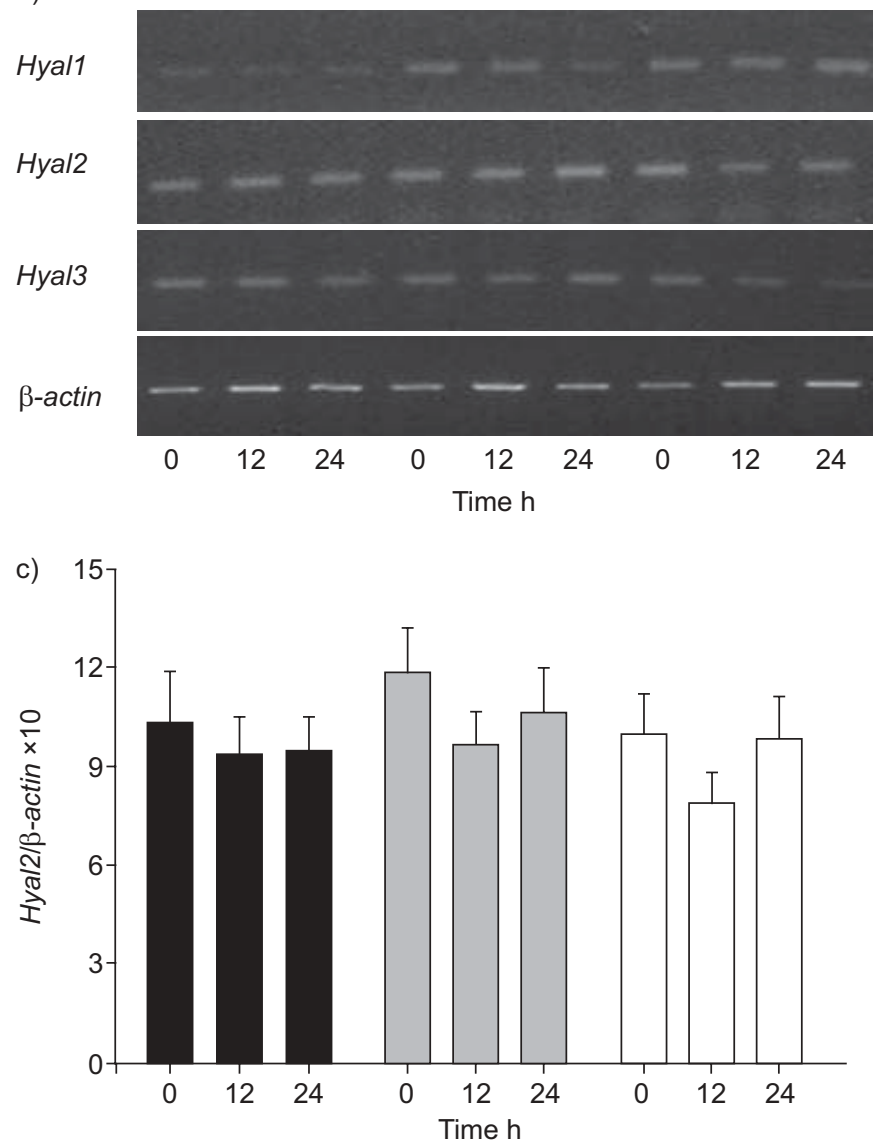

e)

HYAL1

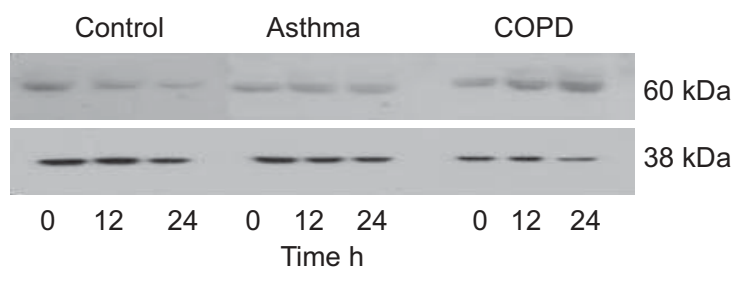

GAPDH

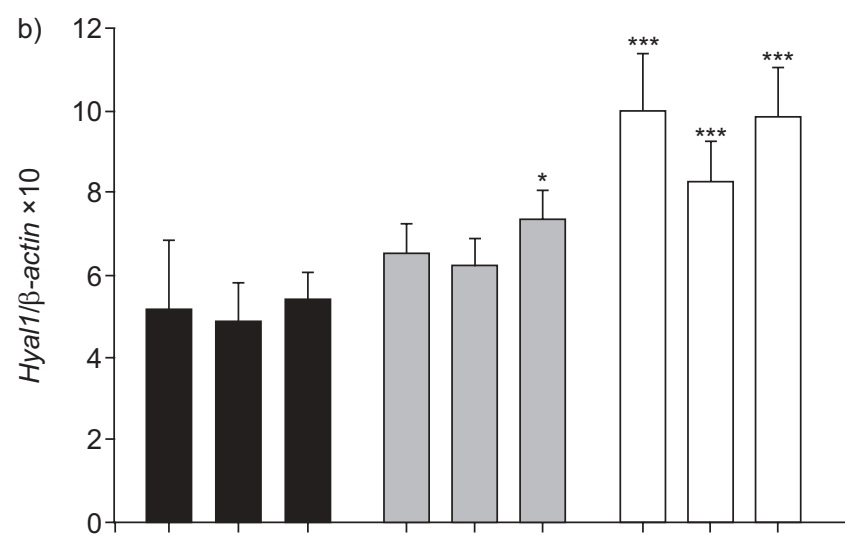

d) $10_{7}$

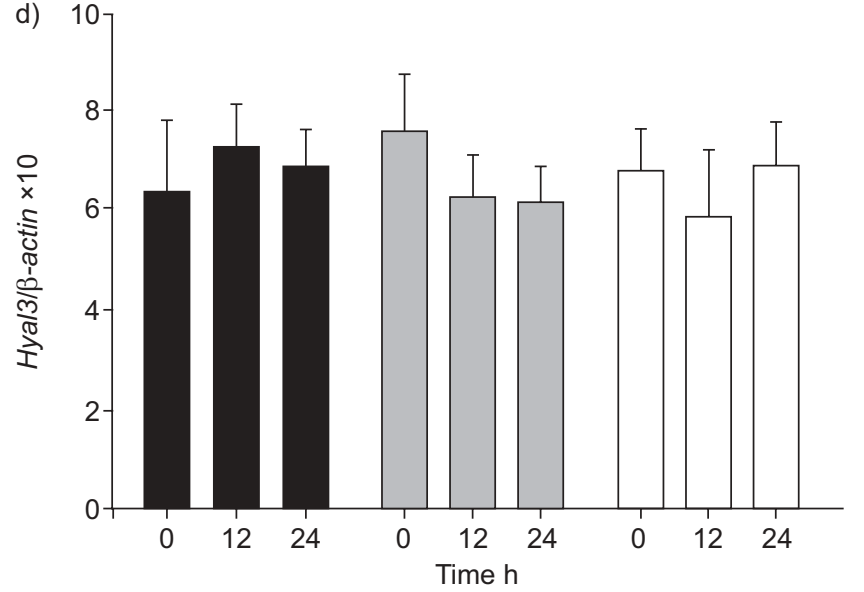

FIGURE 4. Disease-specific expression of hyaluronidases (Hyal) by airway smooth muscle cells (ASMC). a) Representative mRNA expression of Hyal1, Hyal2, Hyal3 and

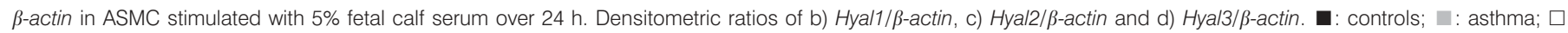
chronic obstructive pulmonary disease (COPD). *: $p<0.05$; ${ }^{* *}: p<0.001$. Statistical differences indicated are between controls and asthma or COPD at each time-point. Error bars represent the mean \pm SEM of triplicate determinations of the Hyal/ $\beta$-actin ratio calculated from ASMC established from 10 healthy donors, 11 asthma and six COPD patients. e) Representative HYAL1 protein levels investigated by Western blotting. Glyceraldehyde-3-phosphate dehydrogenase (GAPDH) served as a loading control.

hyperplasia; mucous metaplasia; vascular abnormalities; and thickening of the airway wall [2]. However, several issues of airway remodelling associated with asthma and COPD remain to be clarified. These include the sequence of the molecular and cellular events involved, the contribution of each facet of the remodelling processes to the clinical symptoms and pathology, and the possibility that airway remodelling represents a healing and repair response to aspects of the pathogenesis. Furthermore, the precise contribution of the individual ECM molecules to airway remodelling that generates the asthma or COPD phenotype has not been adequately defined. Herein, we attempted to clarify the latter, and we have presented data on the differential turnover of HA in AMSC of different origin, employing healthy lung tissue as the basic control condition.
ASMC obtained from patients with asthma or COPD secreted lower amounts of fragmented HA, and this was associated with decreased gene and protein expression of HAS1 and HAS2, increased gene and protein expression of HYAL1, decreased gene and protein expression of CD44 and lack of the HA receptor RHAMM, as compared with ASMC from normal lung tissue. Lower levels of HA in ASMC implicate a reduction of tissue-water content and flexibility, which may contribute to the extended bronchoconstriction and stiffness of the airways in asthma and COPD.

Heparin, dermatan and CS, as well as HA, were present in ASMC from controls and patients with asthma or COPD. These results are in agreement with the reported presence of 


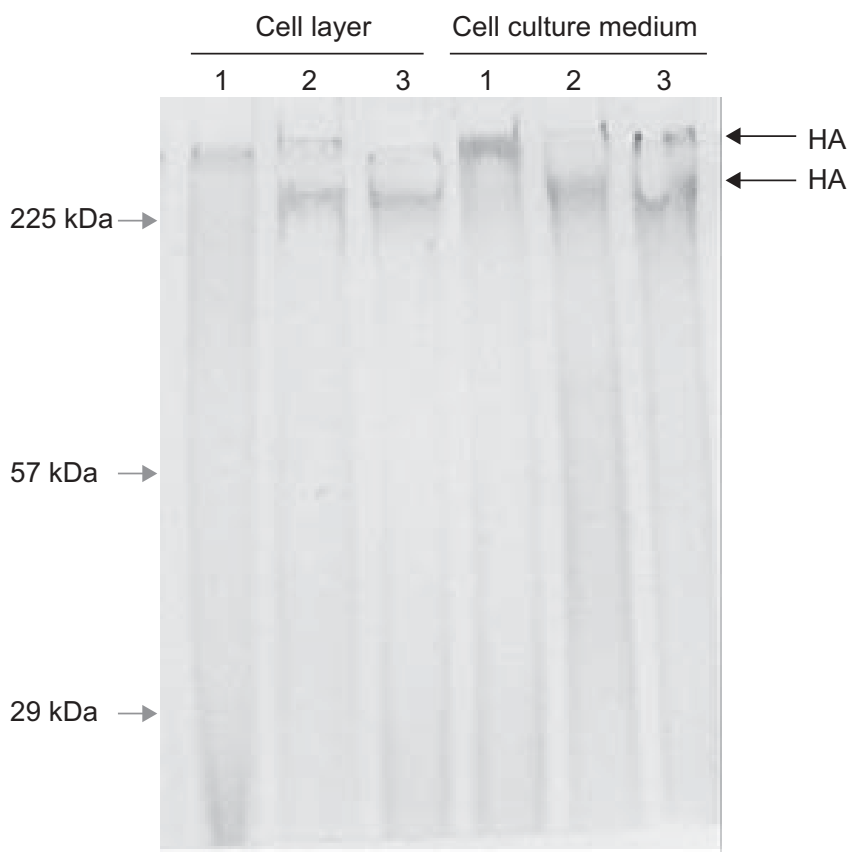

FIGURE 5. Determination of the molecular mass of hyaluronic acid (HA) by $4 \%$ PAGE in the cell layer and the cell culture medium. Representative results obtained after PAGE of total glycosaminoglycan (GAG) corresponding to $4 \mu \mathrm{g}$ of uronic acids. Gels were stained with Alcian blue and the migration of HA, identified by hyaluronidase treatment, is indicated by black arrows. The grey arrows indicate migration of GAG with known molecular mass. Lane 1: control; lane 2: asthma; lane 3: chronic obstructive pulmonary disease.

heparin, chondroitin and DS in tracheal tissue sections [9] and of HA in the human lung [11-13]. However, we observed that total GAG synthesis was reduced in ASMC from asthma and COPD patients when compared with controls. This may be ascribed to the decreased net content of $\mathrm{HA}$ or to the decreased concentration of HA relative to total GAG in diseased ASMC. The decreased secretion or deposition of HA was apparently due to both a decrease in HA synthesis and an increase in HA degradation, since RTPCR analysis and immunoblotting revealed a significant reduced expression of HAS1 and HAS2 and a significant increased expression of HYAL1 in ASMC from patients with asthma and COPD, as compared to controls. Our results provide evidence that reduced levels of HA are associated with asthma and COPD.

How could reduced levels of HA contribute to the pathogenesis of asthma and COPD? Indeed, there is considerable evidence that HA has a pleiotropic protective role in the lung. HA possess a unique capacity to link and retain water molecules in the inter-fibrillar space via osmotic pressure and flow resistance and, thus, contributes to the structure of the amorphous colloidal matrix which glues together cells and connective fibres [10]. This provides HA with the ability to hydrate and control solute transport and microcirculatory exchanges, due to its influence on interstitial volume, hydraulic conductibility and macromolecule diffusion [28]. Other physiological functions of HA include the interaction with proteins by sieve and exclusion effects (barrier effect), stabilisation of the ECM structure by electrostatic interactions, lubrication through its rheological properties, increased mucociliary clearance and prevention of elastin degradation [10]. Furthermore, in the healthy lung HA stimulates ciliary clearance, retains homeostatic enzymes at the apical surface, and binds and stabilises lung surfactant molecules [29]. HA stabilises proteoglycans in the ECM [30], contributes to tissue repair [20], inhibits migration, chemotaxis and aggregation of polymorphonuclear leukocytes and monocytes [31], and prevents elastase degradation of pulmonary elastin by a mechanism of protective coating [32].

The biological functions of HA point to a protective role in the bronchial tissue, which correlates with our observation that $\mathrm{HA}$ is decreased in ASMC from asthma and COPD patients. In this context, HA blocked acute bronchoconstriction caused by human neutrophil elastase in sheep [33], and a single dose of inhaled HA was suggested to protect against exercise-induced bronchoconstriction in asthma patients [12]. Furthermore, in COPD patients [34] or elastase-induced emphysema [35], treatment with HA had beneficial effects. It is of interest that two other GAG, heparin and HS, have also been reported to be beneficial during asthma therapy by a mechanism of action that is not directly related to their anticoagulant property [36].

In contrast to the protective role of HA in lung physiology, it has also been reported that: serum levels of HA did not differ between patients with asthma or wheeze compared with normal controls [37]; inhaled low molecular mass HA $\left(0.15 \times 10^{6} \mathrm{kDa}\right)$ did not significantly protect against exerciseinduced bronchoconstriction in asthmatic patients [38]; and there are increased levels of HA in lung secretions of asthma [39] and COPD [13] patients. However, these apparently contradictory reports may be explained as follows: 1) HA serum levels may not necessarily reflect HA levels in the lung; 2) it is the high molecular mass HA that exerts beneficiary effects; 3) lower molecular mass HA $\left(0.3-0.5 \times 10^{6} \mathrm{kDa}\right)$ predominate under inflammatory conditions [14]; 4) the increased levels of HA in lung secretions of asthma and COPD patients may reflect enhanced degradation and subsequent secreation of $\mathrm{HA}$, as a consequence of the increased expression of Hyal2 in COPD patients [13] and Hyal1 in ASMC that we report here.

The argument for a protective role of HA of high molecular mass in the lung is further supported by reports that HA of high but not of low molecular mass inhibited the function of alveolar [40] and peritoneal macrophages [41] and that goblet cell metaplasia induced by reactive oxygen species in normal human bronchial epithelial cells was associated with HA depolymerisation [42]. Furthermore, HA of low but not high molecular mass prolonged the survival of eosinophils, stimulated the synthesis of transforming growth factor- $\beta_{1}$ in vitro [43], and induced the expression of cytokines, chemokines and inducible nitric oxide synthase by macrophages [44].

With respect to the size of HA, we observed that ASMC from patients with asthma or COPD expressed HA of lower molecular mass compared with controls. This may be the result of: 1) the increased expression at gene and protein levels of HYAL1 in asthma and COPD; and 2) the reduced expression of HAS1 and HAS2 since it has been shown that the catalytic 

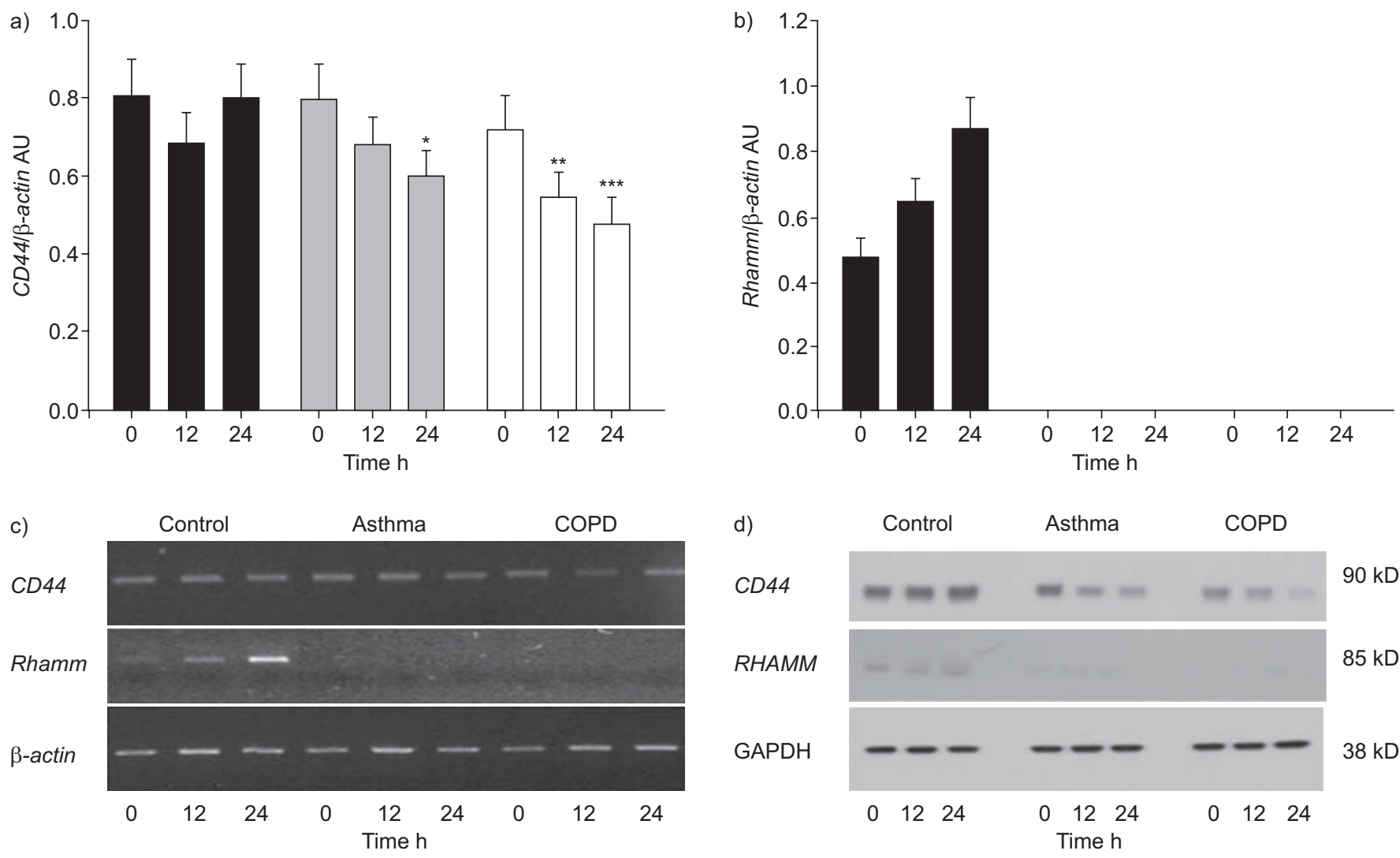

$90 \mathrm{kDa}$

$85 \mathrm{kDa}$

$38 \mathrm{kDa}$

FIGURE 6. Disease-specific expression of hyaluronic acid (HA) receptors by airway smooth muscle cells (ASMC). Densitometric ratios of a) CD44/ $\beta$-actin and b) receptor for HA-mediated motility (Rhamm)/ $\beta$-actin. $\mathbf{\square}$ : controls; $\square$ : asthma; $\square$ : chronic obstructive pulmonary disease (COPD). Error bars represent the mean \pm SEM of triplicate determinations from ASMC of 10 donors, 11 asthma and six COPD patients. *: $p<0.05$; $* *: p<0.01 ; * \star *: p<0.001$. Statistical differences indicated are between controls and asthma or COPD at each time-point. c) Representative mRNA expression of CD44, Rhamm and $\beta$-actin in ASMC after stimulation with $5 \%$ fetal calf serum over 24 h. d) Representative CD44 and RHAMM protein levels investigated by Western blotting. Glyceraldehyde-3-phosphate dehydrogenase (GAPDH) served as a loading control.

rates and the final molecular weight product of $\mathrm{HA}$ are different for the three HAS isoforms [45]. HAS1 is the least active, and produces HA of $0.2-2.0 \times 10^{6} \mathrm{kDa}$, whilst HAS2 produces similar-sized HA fragments but is more catalytically active. Finally, HAS3 produces smaller HA fragments no larger than $0.1 \times 10^{6} \mathrm{kDa}$, and may be involved in activation of signal transduction [46].

The wide range of functions of HA in different cell types is mediated through its receptors, CD44 and RHAMM [16, 17]. Our data show that CD44 was reduced in ASMC from asthma or COPD patients compared with controls, while RHAMM was not expressed at the gene or protein level. It has been shown that CD44 is the major cell-surface hyaluronan receptor and is required to clear hyaluronan degradation products produced during lung injury [47]. Therefore, it may be postulated that the reduced expression of CD44 that we report in asthma and COPD may be associated with impaired clearance of hyaluronan of low molecular mass from the lung, resulting in persistent inflammation.

HA also binds to RHAMM, which controls the effect of HA on cell migration, proliferation and motility, apparently via RHAMM interaction with the cytoskeleton [48, 49]. It remains to be elucidated if lack of RHAMM in asthma and COPD is associated with impaired function of HA in the lung, which may result in pathophysiological changes leading to the diseases.

In conclusion, the available literature and the results presented here, using healthy lung tissue as the basic control condition, indicate that HA of high molecular mass is involved in physiological aspects of lung function, while it is the fragmented HA, due to reduced expression of HAS1, HAS2 and increased expression of HYAL1, which contributes to the inflammatory processes in asthma and COPD pathology.

\section{SUPPORT STATEMENT}

This study was supported by a grant from the General Secretariat for Research and Technology of Greece (03E $\Delta 950)$ and by a Swiss National Foundation grant (3200B0-105737/1).

\section{STATEMENT OF INTEREST}

None declared.

\section{ACKNOWLEDGEMENTS}

We would like to thank C. Pourzitaki for her valuable assistance in performing the statistical analysis of our data. 


\section{REFERENCES}

1 Johnson PR, Roth M, Tamm M, et al. Airway smooth muscle cell proliferation is increased in asthma. Am J Respir Crit Care Med 2001; 164: 474-477.

2 Postma DS, Timens W. Remodeling in asthma and chronic obstructive pulmonary disease. Proc Am Thorac Soc 2006; 3: 434-439.

3 Trian T, Benard G, Begueret $H$, et al. Bronchial smooth muscle remodeling involves calcium-dependent enhanced mitochondrial biogenesis in asthma. J Exp Med 2007; 204: 3173-3181.

4 Bush A. How early do airway inflammation and remodeling occur? Allergol Int 2008; 57: 11-19.

5 Turato G, Barbato A, Baraldo S, et al. Nonatopic children with multitrigger wheezing have airway pathology comparable to atopic asthma. Am J Respir Crit Care Med 2008; 178: 476-482.

6 Wechsler ME. Bronchial thermoplasty for asthma: a critical review of a new therapy. Allergy Asthma Proc 2008; 29: 365-370.

7 Cox G, Thomson NC, Rubin AS, et al. Asthma control during the year after bronchial thermoplasty. N Engl J Med 2007; 356: 1327-1337.

8 Papakonstantinou E, Karakiulakis G, Eickelberg O, et al. A $340 \mathrm{kDa}$ hyaluronic acid secreted by human vascular smooth muscle cells regulates their proliferation and migration. Glycobiology 1998; 8: 821-830.

9 Monzon ME, Casalino-Matsuda SM, Forteza RM. Identification of glycosaminoglycans in human airway secretions. Am J Respir Cell Mol Biol 2006; 34: 135-141.

10 Fraser JR, Laurent TC, Laurent UB. Hyaluronan: its nature, distribution, functions and turnover. J Intern Med 1997; 242: 27-33.

11 Hallgren R, Eklund A, Engstrom-Laurent A, et al. Hyaluronate in bronchoalveolar lavage fluid: a new marker in sarcoidosis reflecting pulmonary disease. $\mathrm{Br}$ Med J 1985; 290: 1778-1781.

12 Petrigni G, Allegra L. Aerosolised hyaluronic acid prevents exercise-induced bronchoconstriction, suggesting novel hypotheses on the correction of matrix defects in asthma. Pulm Pharmacol Ther 2006; 19: 166-171.

13 Dentener MA, Vernooy JH, Hendriks S, et al. Enhanced levels of hyaluronan in lungs of patients with COPD: relationship with lung function and local inflammation. Thorax 2005; 60: 114-119.

14 Poole AR, Dieppe P. Biological markers in rheumatoid arthritis. Semin Arthritis Rheum 1994; 23: 17-31.

15 Itano $\mathrm{N}$, Sawai $\mathrm{T}$, Yoshida $\mathrm{M}$, et al. Three isoforms of mammalian hyaluronan synthases have distinct enzymatic properties. J Biol Chem 1999; 274: 25085-25092.

16 Esnault S, Malter JS. Hyaluronic acid or TNF- $\alpha$ plus fibronectin triggers granulocyte macrophage-colony-stimulating factor mRNA stabilization in eosinophils yet engages differential intracellular pathways and mRNA binding proteins. J Immunol 2003; 171: 6780-6787.

17 Savani RC, Wang C, Yang B, et al. Migration of bovine aortic smooth muscle cells after wounding injury. The role of hyaluronan and RHAMM. J Clin Invest 1995; 95: 1158-1168.

18 Hall CL, Yang B, Yang X, et al. Overexpression of the hyaluronan receptor RHAMM is transforming and is also required for $\mathrm{H}$-ras transformation. Cell 1995; 82: 19-26.

19 Antonelli A, D'Amore PA. Density-dependent expression of hyaluronic acid binding to vascular cells in vitro. Microvasc Res 1991; 41: 239-251.

20 Toole BP. Glycosaminoglycans and morphogenesis. In: Hay ED, ed. Cell Biology and Extracellular Matrix. New York, Plenum Press, 1991; pp. 259-294.

21 Toole BP. Hyaluronan: from extracellular glue to pericellular cue. Nat Rev Cancer 2004; 4: 528-539.

22 Johnson PR, Armour CL, Carey D, et al. Heparin and PGE2 inhibit DNA synthesis in human airway smooth muscle cells in culture. Am J Physiol Lung Cell Mol Physiol 1995; 269: L514-L519.

23 Papakonstantinou E, Kouri FM, Karakiulakis G, et al. Increased hyaluronic acid content in idiopathic arterial hypertension. Eur Respir J 2008; 32: 1504-1512.
24 Papakonstantinou E, Karakiulakis G, Roth M, et al. Plateletderived growth factor stimulates the secretion of hyaluronic acid by proliferating human vascular smooth muscle cells. Proc Natl Acad Sci USA 1995; 92: 9881-9885.

25 Bitter T, Muir HM. A modified uronic acid carbazole reaction. Anal Biochem 1962; 4: 330-334.

26 Papakonstantinou E, Roth M, Block LH, et al. The differential distribution of hyaluronic acid in the layers of human atheromatic aortas is associated with vascular smooth muscle cell proliferation and migration. Atherosclerosis 1998; 138: 79-89.

27 Papakonstantinou E, Misevic GN. Isolation and characterization of a new class of acidic glycans implicated in sea urchin embryonal cell adhesion. J Cell Biochem 1993; 53: 98-113.

28 Reed RK, Laurent UB. Turnover of hyaluronan in the microcirculation. Am Rev Respir Dis 1992; 146: Suppl. 2, S37-S39.

29 Forteza R, Lieb T, Aoki T, et al. Hyaluronan serves a novel role in airway mucosal host defense. FASEB J 2001; 15: 2179-2186.

30 Rosenberg RC, Varma R. An overview of proteoglycans in physiology and pathology. In: Varma RS, Varma R, eds. Glycosaminoglycans and Proteoglycans in Physiological and Pathological Processes of Body Systems. Basel, Karger, 1982; pp. 1-4.

31 Partsch G, Schwarzer C, Neumuller J, et al. Modulation of the migration and chemotaxis of PMN cells by hyaluronic acid. Z Rheumatol 1989; 48: 123-128.

32 Cantor JO, Cerreta JM, Armand G, et al. The pulmonary matrix, glycosaminoglycans and pulmonary emphysema. Connect Tissue Res 1999; 40: 97-104.

33 Scuri M, Abraham WM. Hyaluronan blocks human neutrophils elastase (HNE)-induced airway responses in sheep. Pulm Pharmacol Ther 2003; 16: 335-340.

34 Venge P, Pedersen B, Hakansson L, et al. Subcutaneous administration of hyaluronan reduces the number of infectious exacerbations in patients with chronic bronchitis. Am J Respir Crit Care Med 1996; 153: 312-316

35 Cantor JO, Cerreta JM, Keller S, et al. Modulation of airspace enlargement in elastase-induced emphysema by intratracheal instillment of hyaluronidase and hyaluronic acid. Exp Lung Res 1995; 21: 423-426.

36 Kanabar V, Hirst SJ, O'Connor BJ, et al. Some structural determinants of the antiproliferative effect of heparin-like molecules on human airway smooth muscle. Br J Pharmacol 2005; 146: 370-377.

37 Fuji Y, Shima M, Ando M, et al. Effect of air pollution and environmental tobacco smoke on serum hyaluronate concentrations in school children. Occup Environ Med 2002; 59: $124-128$.

38 Kunz LI, van Rensen EL, Sterk PJ. Inhaled hyaluronic acid against exercise-induced bronchoconstriction in asthma. Pulm Pharmacol Ther 2006; 19: 286-291.

39 Sahu S, Lynn WS. Hyaluronic acid in the pulmonary secretions of patients with asthma. Biochem J 1978; 173: 565-568.

40 Shannon BT, Love SH. Additional evidence for the role of hyaluronic acid in the macrophage disappearance reaction. Immunol Commun 1980; 9: 735-746.

41 Forrester JV, Balazs EA. Inhibition of phagocytosis by high molecular weight hyaluronate. Immunology 1980; 40: 435-446.

42 Casalino-Matsuda SM, Monzón ME, Forteza RM. Epidermal growth factor receptor activation by epidermal growth factor mediates oxidant-induced goblet cell metaplasia in human airway epithelium. Am J Respir Cell Mol Biol 2006; 34 581-591.

43 Ohkawara Y, Tamura G, Iwasaki $\mathrm{T}$, et al. Activation and transforming growth factor- $\beta$ production in eosinophils by hyaluronan. Am J Respir Cell Mol Biol 2000; 23: 444-451.

44 McKee CM, Penno MB, Cowman M, et al. Hyaluronan (HA) fragments induce chemokine gene expression in alveolar 
macrophages. The role of HA size and CD44. J Clin Invest 1996; 98 : 2403-2413.

45 Itano N, Kimata K. Mammalian hyaluronan synthases. IUBMB Life 2002; 54: 195-199.

46 Slevin M, Krupinski J, Gaffney J, et al. Hyaluronan-mediated angiogenesis in vascular disease: uncovering RHAMM and CD44 receptor signaling pathways. Matrix Biology 2007; 26: 58-68.
47 Teder $\mathrm{P}$, Vandivier RW, Jiang D, et al. Resolution of lung inflammation by CD44. Science 2002; 296: 155-158.

48 Savani RC, Wang C, Yang B, et al. Migration of bovine aortic smooth muscle cells after wounding injury. The role of hyaluronan and RHAMM. J Clin Invest 1995; 95: 1158-1168.

49 Turley AE, Noble WP, Bourguignon YWL. Signaling properties of hyaluronan receptors. J Biol Chem 2002; 277: 4589-4592. 